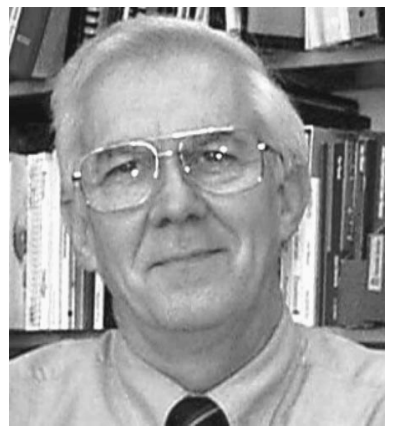

\section{The Professional Connection}

Part of the transition from graduate student to professional is the experience of presenting thesis research to a professional group at a conference. This experience introduces a student to the larger community, establishes the first entry to what may be a long line of references, and expands the student's horizons to the possibilities in the field.

My own introduction to scientific research was a spring meeting of the American Physical Society (APS) in Washington, DC. As I remember it, I had too many slides and ran over my time. The chair was indulgent for a while, but eventually he had to end my presentation. These days it's rare that a graduate student gets a chance to run overtime, because most student papers are given in poster sessions. That's probably for the best. There are more interactions between a student and interested researchers in this format than a 12-minute session explaining transparencies in a darkened room.

These comments are occasioned by the Centennial meeting of the APS held in Atlanta on March 20-26, 1999. Because it was held in my hometown, I represented SPIE's President, Paul Schenker, at the festivities. It was a pleasure to go. I saw some old friends including Leonard Jossem. I got my first taste of real physics research in his lab at Ohio State.

The Centennial meeting combined the celebratory festivities with the March meeting of the Condensed Matter Division, or what used to be called the Solid State meeting. While the celebration was taking place at the beginning of the week, the meat and potatoes part of the program was cranking up, generating the strong energy and demonstrating that condensed matter physics has enormous vitality.

This vitality was noted by the current president of APS, Jerome Friedman of MIT. He compared the enthusiasm of the meeting, engendered by the solid staters, to the early APS meetings that he attended. I knew what he was speaking about. In my graduate student days at Johns Hopkins and my early years at Georgia Tech, the January meeting in New York and the Spring meeting in Washington were standard dates on a physics researcher's calendar. Laser-based research was just getting started and there were lots of opportunities to apply the technology.
Having not attended an APS meeting for many years, I was struck by the size of the meeting. The APS Bulletin that listed all 8700 papers with full abstracts ran over 2000 pages. Attendees walking through the Georgia World Congress Center looked like they were compelled to carry Atlanta phone books. There always has been a buzz at the March meetings even when I was disguised as a laser Raman spectroscopist working on synthetic metalloporphyrins. But, from what I understand, these days this does not transmit to other areas of physics. There the air is more rarified and the search for not just the new, but the novel and/or Nobel, generates a strained atmosphere in which some physicists stand about sniffing the winds for The Next Big Thing.

I no longer am a member of the APS. Over the years I have made my way from the APS to OSA and then to SPIE. In the course of my research career I have always maintained membership with at least one professional organization. This is not a matter of altruism, but a point of professional responsibility. Through membership in SPIE I am wired into the sequence of meetings and notices, a survey of the field in OE Reports, and Optical Engineering, of course. Through OSA, I keep current with other parts of optics.

I have always encouraged my students to join a professional society when they finish their studies. Whether it is OSA or SPIE depends on what they are doing and where they feel their interests lie. (If the unification of the societies takes place it will make it a lot easier to convince potential junior members to join a professional optical society!) But plunking down their money to get some useful journals will not provide them with full value. It is only through attendance at meetings and participation in the society activities that they get their money's worth. But this is also true for those who are fully launched in a career in optical science and engineering. There are volunteer activities in organizing conferences, serving on committees, and contributing papers that can extend your interests and connections beyond your immediate colleagues. Consider your professional connection with SPIE. Are you taking full advantage of your membership and your society? 